\title{
THERMAL PERFORMANCE OF A DUAL-CHANNEL, HELIUM-COOLED, TUNGSTEN HEAT EXCHANGER
}

\author{
Dennis L. Youchison \\ Sandia National Laboratories \\ P.O. Box 5800, MS-1129 \\ Albuquerque, NM 87185, USA \\ (505) $845-3138$
}

\author{
Mark T. North \\ Thermacore, Inc. \\ 780 Eden Road \\ Lancaster, PA 17601, USA \\ (717) $569-6551$
}

\begin{abstract}
Helium-cooled, refractory heat exchangers are now under consideration for first wall and divertor applications. These refractory devices take advantage of high temperature operation with large delta-Ts to effectively handle high heat fluxes. The high temperature helium can then be used in a gas turbine for high-efficiency power conversion.
\end{abstract}

Over the last five years, heat removal with helium was shown to increase dramatically by using porous metal to provide a very large effective surface area for heat transfer in a small volume. Last year, the thermal performance of a bare-copper, dual-channel, helium-cooled, porous metal divertor mock-up was evaluated on the $30 \mathrm{~kW}$ Electron Beam Test System at Sandia National Laboratories. The module survived a maximum absorbed heat flux of 34.6 $\mathrm{MW} / \mathrm{m}^{2}$ and reached a maximum surface temperature of $593{ }^{\circ} \mathrm{C}$ for uniform power loading of $3 \mathrm{~kW}$ absorbed on a $2-\mathrm{cm}^{2}$ area. An impressive $10 \mathrm{~kW}$ of power was absorbed on an area of $24 \mathrm{~cm}^{2}$.

Recently, a similar dual-module, helium-cooled heat exchanger made almost entirely of tungsten was designed and fabricated by Thermacore, Inc. and tested at Sandia. A complete flow test of each channel was performed to determine the actual pressure drop characteristics. Each channel was equipped with delta- $P$ transducers and platinum RTDs for independent calorimetry. One mass flow meter monitored the total flow to the heat exchanger, while a second monitored flow in only one of the channels.

The thermal response of each tungsten module was obtained for heat fluxes in excess of $5 \mathrm{MW} / \mathrm{m}^{2}$ using $50^{\circ} \mathrm{C}$ helium at $4 \mathrm{MPa}$. Fatigue cycles were also performed to assess the fracture toughness of the tungsten modules. A description of the module design and new results on flow instabilities are also presented.

\section{INTRODUCTION}

Over the past five years, dramatic improvements in the power handling capabilities of helium-cooled heat exchangers have occurred due to advanced applications of extended surface technologies such as microchannels and porous metal media. ${ }^{1,2}$ Last year, a dual-channel, copper, porous metal heat exchanger (PMHX) survived heat fluxes as high as $34.6 \mathrm{MW} / \mathrm{m}^{2}$ over a $2 \mathrm{~cm}^{2}$ area with no evidence of parallel flow instabilities. ${ }^{3}$ Effective convective heat transfer coefficients as high as $20,000 \mathrm{~W} / \mathrm{m}^{2} \mathrm{~K}$ were achieved for this copper device making helium performance comparable to water. ${ }^{4}$

Helium-cooled refractory devices are now under consideration in the Advanced Power Extraction (APEX) study that take advantage of high temperature operation with large delta-Ts to utilize the high-efficiency power conversion available from new generation gas turbines. ${ }^{5}$ It is envisioned that such a heat exchanger can be used as the heat sink on monolithic first wall and tungsten rod-armored plasma facing components (pfcs). Such components can accommodate significant heat fluxes by operating over a broad temperature range from $600{ }^{\circ} \mathrm{C}$ to $1500^{\circ} \mathrm{C}$.

However, operation at high temperature requires that the heat exchanger be made entirely of refractory materials. Unfortunately, refractory metals are brittle and suffer from recrystallization and thermally induced stress cracking. In addition, economical fabrication of refractory heat exchangers is challenging at best and does require further development. The use of porous media to enhance heat transfer while minimizing machining costs appears very promising. This article describes the design and fabrication of a tungsten heat exchanger by Thermacore, Inc. and Sandia National Laboratories. The thermal performance, thermal fatigue behavior and the effect of parallel flow instabilities were characterized using the Electron Beam Test System ${ }^{6}$ (EBTS) as a source of onesided heating.

This new refractory heat exchanger satisfied two major objectives. First, dual modules were designed to handle first wall heat loads and fabricated exclusively of high temperature materials. Secondly, test data were obtained that indicate good thermal performance, good fatigue resistance and lack of parallel flow instabilities.

Flow instabilities in the tungsten porous media can be caused by porosity differences in the media of each channel and density reductions due to non-uniform heating. Although little evidence of flow instabilities was found in copper PMHXs, ${ }^{3}$ refractory devices can operate with much 


\section{DISCLAIMER}

This report was prepared as an account of work sponsored by an agency of the United States Government. Neither the United States Government nor any agency thereof, nor any of their employees, make any warranty, express or implied, or assumes any legal liability or responsibility for the accuracy, completeness, or usefulness of any information, apparatus, product, or process disclosed, or represents that its use would not infringe privately owned rights. Reference herein to any specific commercial product, process, or service by trade name, trademark, manufacturer, or otherwise does not necessarily constitute or imply its endorsement, recommendation, or favoring by the United States Government or any agency thereof. The views and opinions of authors expressed herein do not necessarily state or reflect those of the United States Government or any agency thereof. 


\section{DISCLAIMER}

Portions of this document may be illegible in electronic image products. Images are produced from the best available original document. 
higher inlet temperatures and delta-Ts an order of magnitude higher. This leads to even larger reductions in density inside the hot leg and subsequent reductions in mass flow. Flow bypass in a parallel cold leg may be a serious concern. The mass flow increases in the colder leg to maintain the same pressure drop. Unfortunately, such a situation decreases the cooling to the hot areas, while increasing it to the cold areas. During plasma disruptions or other off-normal events, such instability could lead to a catastrophic failure in a poorly designed, helium-cooled pfc.

\section{A. Description of the Modules}

The dual-channel PMHX consisted of two separate modules in parallel flow. Individual parts are identified in Fig. 1. Each module consisted of a tungsten cylindrical cup containing a hemispherical shell of brazed tungsten porous metal. This cup is brazed onto a tungsten cylindrical tube bottomed by a flat tungsten plate that facilitates the brazed attachment of 316 stainless steel supply tubes. The tungsten cylinder acts as the pressure boundary and entrance plenum for the cool helium. The helium flows along the tube walls and enters a hemispherical shell of porous media along its perimeter. The helium then flows radially inward while moving closer to the backside of the heated faceplate. At the apex, the flow is redirected normally away from the faceplate along the vertical axis of the hemisphere where it exits the porous media. A stainless steel bellows connects the exit duct to the exit tube at the bottom of the heat exchanger and segregates the hot and cold gas. This design minimizes pressure drop by absorbing most of the heat near the exit duct, thus reducing the distance that hot gas must travel in the porous media and localizing the gas expansion near the exit.

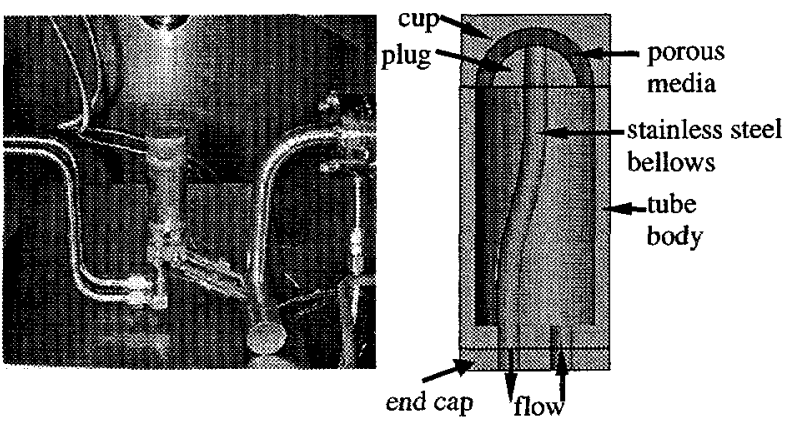

Fig. 1. Two helium-cooled tungsten modules were tested in a parallel flow configuration

\section{B. Assembly of the Modules}

All parts for the tungsten heat exchanger including the porous media were fabricated at Thermacore. However, the final assembly and brazing using a high temperature $11 \%$ P $89 \% \mathrm{~N}$ (NicroBraze ${ }^{\mathrm{TM}}$-10) filler metal were performed at Sandia. The first braze $\left(960{ }^{\circ} \mathrm{C}-5 \mathrm{~min}\right)$ attached the stainless steel bellows to the end cap and the end cap to the body. The second braze $\left(920^{\circ} \mathrm{C}-5 \mathrm{~min}\right)$ attached the cup/plug assembly to the stainless steel bellows and the tungsten body, while simultaneously attaching the stainless steel supply tubes to the end cap.

Microcracks developed in the braze filler metal (BFM) fillets around the stainless steel tube/end cap interface. In an effort to seal the microcracks, another braze at $980^{\circ} \mathrm{C}-$ $10 \mathrm{~min}$ was performed but was unsuccessful.

In another attempt to fill the microcracks, BFM (Palcusil ${ }^{\text {TM}}$-10) was added, and additional brazes were performed at $900^{\circ} \mathrm{C}-10 \mathrm{~min}$ until only a small leak could be detected. At that point, a high temperature, vacuum compatible, epoxy resin was used to seal the end cap near the supply tubes.

In an effort to improve the procedure, the second tungsten module was fabricated in four separate brazing steps, all using BAu-4 (Nioro ${ }^{\mathrm{TM}}$ ) braze filler metal in a dry hydrogen atmosphere. Helium mass spectroscopy leak detection was used after each braze step to insure subassembly integrity.

1. The first step was to braze the stainless steel tube assembly to the tungsten end cap. This braze was accomplished at $1000^{\circ} \mathrm{C}$ for 5 minutes.

2. The next step was to braze the stainless steel bellows assembly to the end cap. Stainless steel fixturing, nickel wire and an alumina rod were used to prohibit inadvertent bellows movement. This braze was performed at $990{ }^{\circ} \mathrm{C}$ for 3 minutes.

3. Next, filler metal preforms were placed on the inside diameter of the tungsten body, and positioned against the end cap. It was necessary to bend the bellows slightly to allow the body to seat properly against the end cap. A leak test was performed after this adjustment, and no leaks were detected. This assembly was brazed at $985{ }^{\circ} \mathrm{C}$ for 5 minutes.

4. The final braze attached the cup/plug subassembly onto the body/end cap assembly as identified in Fig. 1. Braze preforms were made to join the bellows to the tungsten plug, and then the body/end cap subassembly was pressed onto the plug/cup subassembly. This assembly was strapped into place with welded nickel ribbon to eliminate any movement. The braze temperature was $980^{\circ} \mathrm{C}$, and the soak time was 5 minutes.

This completed assembly passed a helium leak test with a leak rate near $1.0 \times 10^{-9} \mathrm{~atm} \mathrm{cc} / \mathrm{s}$.

\section{EXPERIMENT}

\section{A. Apparatus}

A series of thermal response tests was performed on the helium divertor module using the Electron Beam Test System (EBTS) at Sandia National Laboratories. The EBTS, described in detail elsewhere, ${ }^{6}$ is a $30 \mathrm{~kW}$, hot cathode, grid-controlled electron beam system operating at $30 \mathrm{kV}$. The electron beam can be rastered at a frequency

RECEIVED

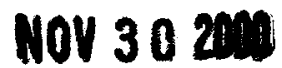


of $10 \mathrm{kHz}$ in both the $\mathrm{x}$ and $\mathrm{y}$ directions and has a spot size of $1.5 \mathrm{~mm}$ in diameter. The EBTS is used to study the thermal response and failure modes of high-heat-flux (HHF) materials and components.

The EBTS is equipped with a closed helium coolant loop (HeFL) which can operate at a maximum pressure of 4.1 $\mathrm{MPa}$ and temperatures as high as $300{ }^{\circ} \mathrm{C} .{ }^{6}$ Helium mass flow rates as high as $22 \mathrm{~g} / \mathrm{s}$ have been achieved for sample pressure drops near $7 \mathrm{kPa}$ and total pressures of 4 MPa. By adjusting the loop blower speed one can produce a constant differential pressure, but cannot provide an independent mass flow rate. The maximum pressure drop for a sample that can maintain a steady flow in the present loop is $55 \mathrm{kPa}$ at $4 \mathrm{MPa}$.

\section{B. Diagnostics}

The tungsten PMHX was connected with a common inlet and separate outlets for each channel. Each of the channels had a differential pressure transducer for pressure drop comparison. The total mass flow rate in the helium loop is calculated from the pressure drop across an orifice using the local pressure and temperature. This device is referred to as the orifice flow meter. Both of the outlets had a valved connection to the inlet of a turbine volumetric flow meter. This valve arrangement, shown in Fig. 2, allowed the flow from each of the channels to be redistributed through the flow meter either separately or in combination. Unfortunately, the turbine flow meter only operates when the helium flow exceeds $5 \mathrm{~g} / \mathrm{s}$ at $4 \mathrm{MPa}$, which was not the case for dual module flow. However, by applying an identical heat flux over each channel in succession and by using proper valving, the system flow, and the pressure drop data, we were able to estimate the flow allocation through each channel.

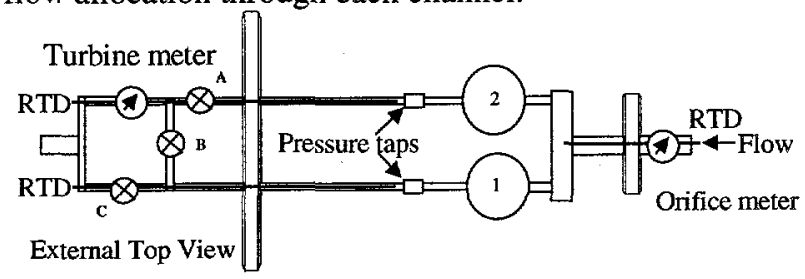

Fig. 2. Three valves were required for flow meter calibration and cross-check.

Calorimetry for the two channels was obtained from the partitioned mass flow rate and the temperature rise of each channel. The temperature rise was determined with the use of three RTD probes inserted in the helium lines, one at the common inlet of the channels and one in each outlet channel. Two other thermocouples were attached to the supply tubes at the bottom of each module. These thermocouples were used to measure the bulk temperature during emissivity calibration of the optical pyrometers and a 3-12 $\mu \mathrm{m}$ broadband infrared camera at $350^{\circ} \mathrm{C}$. Two 1 color pyrometers with overlapping ranges $\left(150-550^{\circ} \mathrm{C}\right.$ and $320-1300^{\circ} \mathrm{C}$ ) were used to measure surface temperatures during heating of the modules.

\section{Procedures}

Unheated flow tests were first conducted on the modules to characterize their pre-test condition using helium at $4.0 \mathrm{MPa}$ absolute pressure. First, module \#2 was installed in parallel with a $10-\mathrm{mm}$-i.d. bypass tube. This permitted enough flow to activate the turbine flow meter. Flow and pressure drop data were accumulated at selected blower speeds for both single and dual-channel flow. While flowing the bypass tube, the turbine flow meter was calibrated to match the flow measured on the delta-P orifice meter. Conservation of mass was used to deduce the flow in the module when the bypass tube was active.

Thermal response curves for both tungsten modules were obtained by using a heated area of $4.9 \mathrm{~cm}^{2}(2.5 \mathrm{~cm}$ in diameter) centered on the $3.2-\mathrm{cm}$-dia faceplate. In each case, a circular raster pattern comprised of 8 interlaced concentric circles of carefully selected radii with a varying number of repetitions was created to provide the most uniform heat flux. Module \#2 was tested first using flow rates of only 1 to $2 \mathrm{~g} / \mathrm{s}$ of helium at $4.0 \mathrm{MPa}$. The module reached steady state calorimetry in 120 to $150 \mathrm{~s}$ at these flowrates. To investigate a worst case scenario for flow bypass, data were obtained for single channel flow through just the module and also for parallel flow through the unheated bypass tube.

The thermal response test of the first tungsten module was performed with it mounted in parallel with the second module. Prior flow testing indicated that the first module had much less pressure drop than the second. Flow rates of 4 to $5 \mathrm{~g} / \mathrm{s}$ of helium at $4.0 \mathrm{MPa}$ were attained throughout the thermal response tests. An identical heated area was used with similar applied heat fluxes. Again to investigate flow instabilities, data were obtained for single flow and also parallel flow through the other unheated tungsten module.

Finally, thermal fatigue cycles were performed on module \#1 at 3.5 To $3.8 \mathrm{MW} / \mathrm{m}^{2}$ absorbed heat flux. The purpose of these cycles was to investigate stress cracking in the 3-mm-thick tungsten faceplate and possibly reveal other thermal fatigue failure modes. The cycles consisted of $25 \mathrm{~s}$ on times where the surface temperature reached about $95 \%$ of the steady state temperature. The cooldown time was 10 s.

\section{RESULTS}

\section{A. Flow Characteristics}

A plot of mass flow vs. pressure drop for each flow configuration under isothermal conditions is shown in Fig. 3. For single channel flow, the results indicate that the second module in channel \#1 consistently had a pressure drop more than four times higher than the first module in channel \#2. This was later found to be a clogging problem. 
During HHF testing, this difference in flow characteristic led to a pronounced difference on the delta-T produced in the helium and on the surface temperature. However, the reduced mass flow had lesser effect on the overall thermal performance and the maximum attainable heat flux.

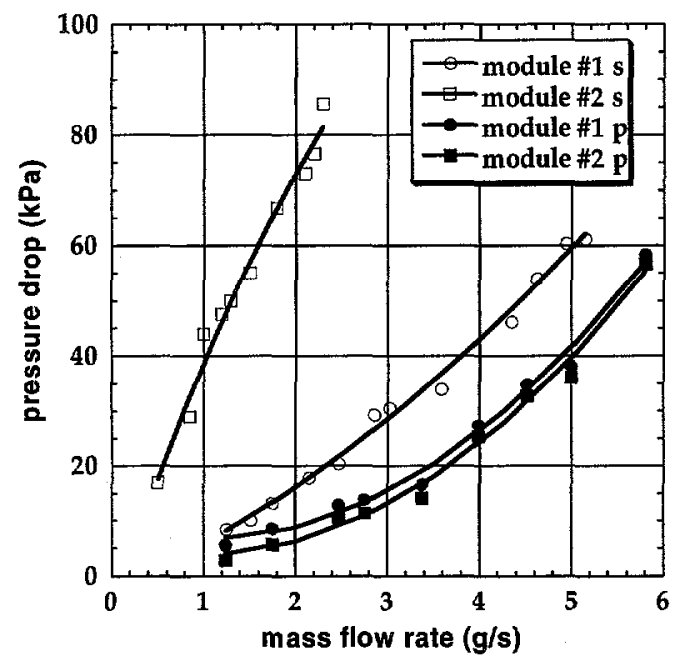

Fig. 3. Flow tests for both single and parallel-channel flow revealed high pressure drops and porosity differences.

In the parallel flow configuration, the pressure drop across both modules was approximately $55 \mathrm{kPa}$ with the flow partitioned appropriately between the two modules. This was the maximum target pressure drop achievable with the HeFL at $4 \mathrm{MPa}$. For the applied head, module \#1 garnered about three times the mass flow as module \#2, or about $75 \%$ of the total flow.

\section{B. Thermal Response}

The thermal response curve for uniform heating on a $4.9 \mathrm{~cm}^{2}$ area centered on module \#2 is shown in Fig. 4 . This figure shows data for both single and parallel flow. The maximum heat flux attained for steady state conditions was $5.5 \mathrm{MW} / \mathrm{m}^{2}$ producing a maximum surface temperature of $934{ }^{\circ} \mathrm{C}$ during single channel flow. The mass flow rate ranged from $1.4 \mathrm{~g} / \mathrm{s}$ down to $1.1 \mathrm{~g} / \mathrm{s}$ at the higher heat fluxes. The maximum delta- $\mathrm{T}$ in the helium was $472{ }^{\circ} \mathrm{C}$ corresponding to a steady state absorbed power in the module of $2700 \mathrm{~W}$.

During parallel flow with a bypass tube, flow redistribution occurred for the highest heat flux levels that resulted in a $39 \%$ reduction in flow to the hot leg. The total loop flow dropped by $31 \%$ and the bypass flow increased by $8 \%$. This phenomenon is illustrated in the data presented in Fig. 5. For a $5.1 \mathrm{MW} / \mathrm{m}^{2}$ heat flux, the surface temperature rose an additional $108{ }^{\circ} \mathrm{C}$ compared to the single channel flow case and the delta- $\mathrm{T}$ in the helium increased by $15{ }^{\circ} \mathrm{C}$. Infrared imaging revealed that the center zone above the exit duct had the highest surface temperatures. The overall power absorption in the helium decreased to only $63 \%$ of the single channel case. For heat fluxes lower than $3 \mathrm{MW} / \mathrm{m}^{2}$ only minor differences in thermal performance between the two flow configurations were observed.

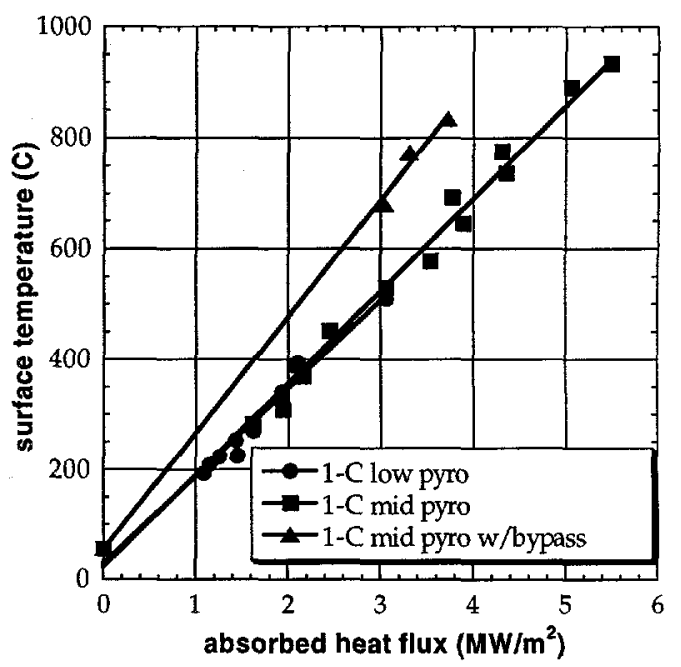

Fig. 4. Surface temperature response for module \#2 in single channel flow and with active bypass (lines are linear fits for single-phase forced convection).

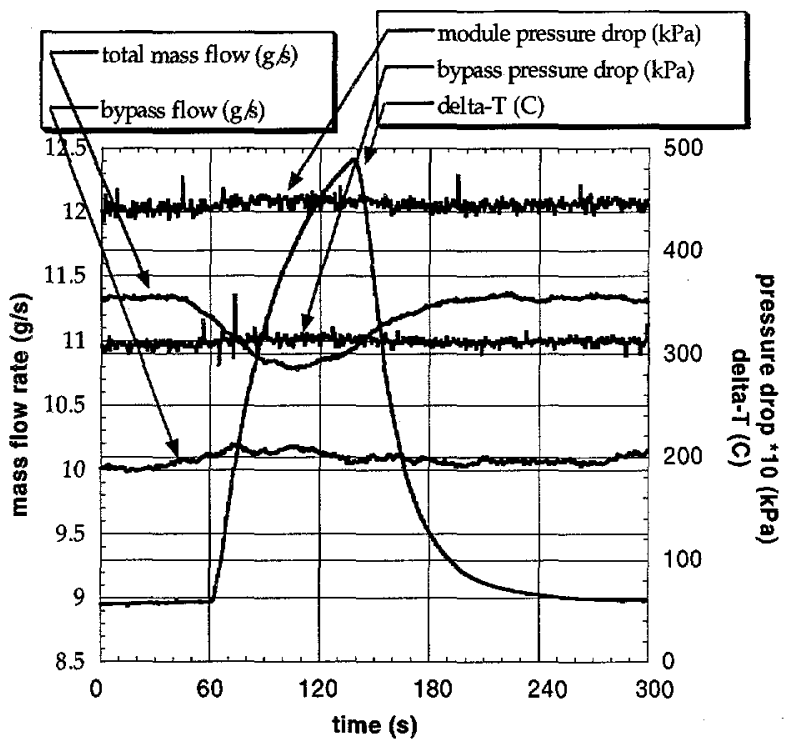

Fig. 5. Evidence of a mass flow instability existed only with a flow bypass tube

The thermal response curves for module \#1 appear in Fig. 6 below. A maximum heat flux of $5.9 \mathrm{MW} / \mathrm{m}^{2}$ was absorbed producing a maximum surface temperature of 840 ${ }^{\circ} \mathrm{C}$. The mass flow rates during this test sequence ranged from $3.8 \mathrm{~g} / \mathrm{s}$ down to $3 \mathrm{~g} / \mathrm{s}$ at the higher heat fluxes. The maximum delta-T in the helium was $189^{\circ} \mathrm{C}$ corresponding to an absorbed steady state power of $2890 \mathrm{~W}$. Virtually identical performance was obtained from the module regardless of whether it was in single channel flow or in parallel flow with module \#2. 


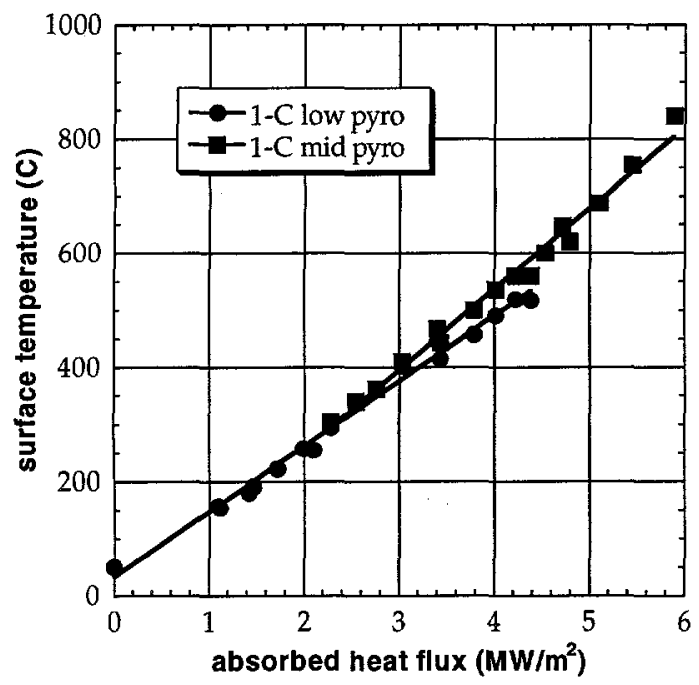

Fig. 6. Surface temperature response for module \#1 in parallel flow with unheated module \#2 (lines are linear fits for single-phase forced convection).

\section{Thermal Fatigue}

Module \#1 survived over 500 thermal cycles at 3.5 to $3.8 \mathrm{MW} / \mathrm{m}^{2}$ with a mass flow rate of 3.4 to $3.6 \mathrm{~g} / \mathrm{s}$. No difference in the thermal performance was noted between the beginning of the cycling and the end. Evidence of microcracking and enhanced porosity of the tungsten in the heated area were observed during post-test inspection. A macroscopic view of the surface presented in Fig. 7 shows the thermal signature created during the thermal response testing of module $\# 2$ at the highest heat fluxes. This was caused by the unintended presence of braze material on the faceplate that re-flowed above $1000^{\circ} \mathrm{C}$.

\section{Post-Test Inspection}

After testing the second module was sectioned longitudinally down the centerline of the porous shell. Fig. 7 is a photograph of a section. Porosity measurements indicated an average porosity of $49 \%$. Fig. 7 also presents an optical micrograph of the heated areas and reveals microcracking of the tungsten surface created by cyclic compressive thermal stresses. Braze metal contaminate is clearly evident on the surface.
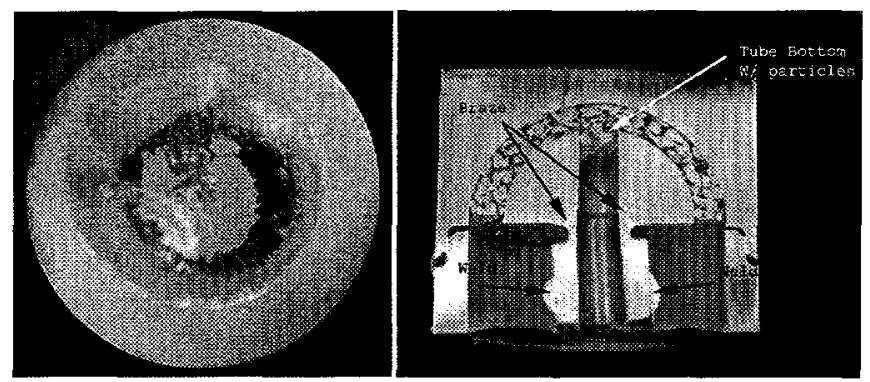

Fig. 7. Post-test photos of modules showing reflow of misplaced braze material on surface.

\section{MODELING AND ANALYSIS}

The COSMOS/M finite element program was used to. determine the effective heat transfer coefficient inside the tungsten module ${ }^{7}$ The module was modeled using 45000 4-node tetrahedral elements. Thermal conductivity of the tungsten was taken as $201 \mathrm{~W} / \mathrm{m} \cdot \mathrm{K}$. Boundary conditions on the module were taken to be adiabatic on all sides except for the inside hemisphere of the cup and the top surface.

Convection to the helium was assumed to be via an effective heat transfer coefficient that varied with angle because of the helium velocity variation from inlet to outlet. The local helium temperature was varied linearly along the quarter-circumference from the inlet to the outlet using the measured helium inlet and outlet temperatures.

One e-beam shot was modeled in detail using the absorbed heat flux of $4.4 \mathrm{MW} / \mathrm{m}^{2}$. The magnitude of the angular dependent heat transfer coefficient on the inside of the cup was adjusted until the maximum calculated surface temperature matched the temperatures indicated by the infrared data. The calculated temperature distribution in an isometric view is shown below in Fig. 8. The heat transfer coefficients consistent with the infrared data for module \#1 varied from $4400 \mathrm{~W} / \mathrm{m}^{2} \cdot \mathrm{K}$ at the inlet to $22,000 \mathrm{~W} / \mathrm{m}^{2} \cdot \mathrm{K}$ at the outlet.

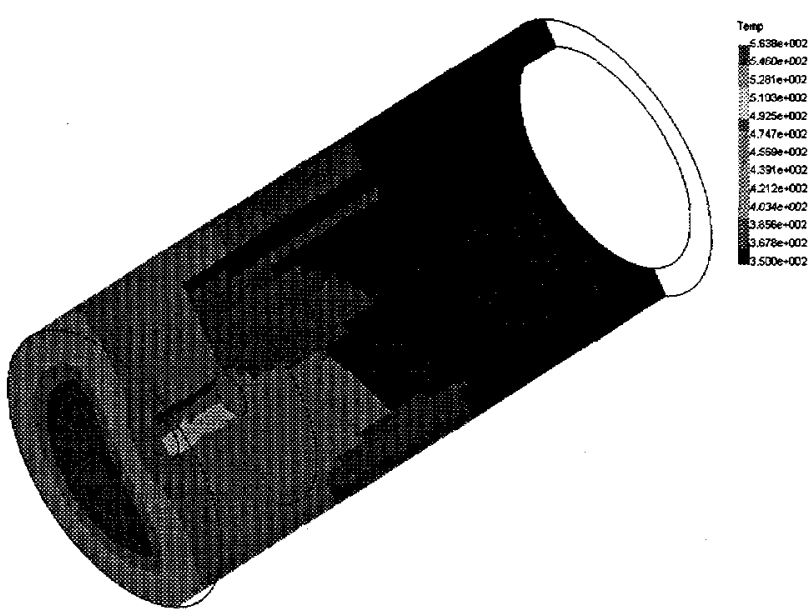

Fig. 8. A steady state temperature profile in an isometric view of module \#1 was obtained by numerical modeling.

\section{CONCLUSIONS}

It is possible to successfully fabricate a robust, allrefractory helium-cooled heatsink using existing porous metal technology. This high temperature heatsink removed substantial amounts of power even at low mass flow rates by taking advantage of large delta-Ts in the coolant. The heatsink survived over 500 thermal fatigue cycles at 3.5 $\mathrm{MW} / \mathrm{m}^{2}$ with only minimal microcracking of the faceplate. Existing tungsten rod armor may be incorporated into the tungsten faceplate in advanced pfc designs without the problems of joining dissimilar materials. 
These heat exchangers exceeded design specifications and survived a maximum heat flux of almost $6 \mathrm{MW} / \mathrm{m}^{2}$ and a maximum surface temperature near $1000^{\circ} \mathrm{C}$. However, the pressure drop across each module was relatively high, exceeding $55 \mathrm{kPa}$. The porosity difference between the two modules in these experiments was as high as $30 \%$. Obviously, there remain problems with controlling porosity and clogging by contaminants.

No evidence of mass flow instabilities was observed for the two modules in parallel even for very high delta-Ts in the helium. Nearly the same thermal response was obtained on each module. However, for a worst case scenario of an unrestricted flow bypass, a $39 \%$ reduction in mass flow occurred in the module resulting in a $37 \%$ reduction in power absorbed by the helium.

This level of thermal performance is more than adequate for $2 \mathrm{MW} / \mathrm{m}^{2}$ first wall applications proposed for solid first walls in APEX and also for the $\mathrm{Li}-\mathrm{He}$ heat exchanger in the Evaporation of Lithium and Vapor Extraction (EVOLVE) concept. ${ }^{5}$ However, better performance could be obtained if the porosity could be doubled. This would almost triple the mass flow and power handling capability. Such an innovation could open a design window into the divertor heat flux regime of 20 to $30 \mathrm{MW} / \mathrm{m}^{2}$ and make high temperature, helium-cooled refractory heatsinks a desirable alternative to liquid metal pfcs.

\section{ACKNOWLEDGMENTS}

The authors would like to recognize the contributions of K.P. Troncosa and M.E. Miszkiel for operation of the EBTS and helium loop. The authors are also indebted to C.A. Walker for performing a difficult braze procedure and producing a leaktight assembly and A.C. Kilgo for the sectioning and metallography measurements.

Sandia is a multiprogram laboratory operated by Sandia Corporation, a Lockheed Martin Company, for the Department of Energy under Contract DE-AC0494AL85000.

\section{REFERENCES}

1. J.H. Rosenfeld and J.E. Lindemuth, "Evaluation of Porous Media Heat Exchangers for Plasma Facing Components," Proc. 1993 IEEE/NPSS 15 ${ }^{\text {th }}$ Symp. Fusion Engineering, Vol. 2, IEEE, Hyannis, Massachusetts, 1993, pp. 1210-1213.
2. M.T. North, J.H. Rosenfeld and D.L. Youchison, "Test Results from a Helium Gas-Cooled Porous Metal Heat Exchanger," in A. Khounsary (ed.) High Heat Flux Engineering III, Vol. 2855, SPIE, 1996, pp. 54-65.

3. D.L. Youchison, M.T. North, J.E. Lindemuth, J.M. McDonald and T.J. Lutz, "Thermal Performance and Flow Instabilities in a Multi-Channel, Helium-Cooled, Porous Metal Divertor Module," $5^{\text {th }}$ Intl. Symp. on Fusion Nucl. Technol., Rome, Italy, September 19-24, 1999. Fusion Engr. \& Design, 48 (in press) (2000).

4. D.L. Youchison, M.G. Izenson, C.B. Baxi and J.H. Rosenfeld, "High-Heat-Flux Testing of Helium-Cooled Heat Exchangers for Fusion Applications," Fusion Technol., 29, 559 (1996).

5. M.A. Abdou et al. "On the Exploration of Innovative Concepts for Fusion Chamber Technology," APEX Interim Report Vol. 2, UCLA, UCLA-ENG-99-206, November 1999, Chpts. 10 and 11.

6. D.L. Youchison, J.M. McDonald, and L.S. Wold, High Heat Flux Testing Capabilities at Sandia National Laboratories - New Mexico, 1994 Winter Annual Meeting. of the ASME, Heat Transfer in High Heat Flux Systems, HTD-Vol. 301, ASME Book No. G00956, 1994, pp. 31-37.

7. Structural Research and Analysis Corp., Santa Monica, CA, v2.0, January, 1998. 